\title{
The Implications of Differences in Chinese and American Discourses in English Writing Teaching in Universities and Colleges in China
}

\author{
Xiong Guofang* \\ School of Foreign Language of Xi'an University \\ Xi'an, China \\ 357141898@qq.com \\ * Corresponding Author
}

\begin{abstract}
There are differences between Chinese and American discourses due to differences in cultures and modes of thinking, and they are of great significance to English writing teaching in universities and colleges. Differences between Chinese and American discourses not only brought many opportunities to English writing teaching, but also difficulties are increased in English writing teaching in universities and colleges. Chinese is hypotaxis in discourse and English is parataxis in discourse, and these discourse differences between Chinese and English are also reflected in cohesions such as the use of substitutions, ellipsis and conjunctions. These differences will directly have influence on English writing teaching and learning effect in universities and colleges, so that this paper aims to provide some guidance for English writing teaching in universities and colleges through the comparison of Chinese and American discourse differences. This paper is a documentary and qualitative research. It can be resulted from the paper that Chinese and American discourse differences are caused by differences between Chinese and American cultures and modes of thinking, and teachers should make full use of these differences to cultivate students' consciousness of discourse cohesions in order to help them write authentic English passages.
\end{abstract}

Keywords-English writing teaching; discourse differences; Chinese and American; universities and colleges

\section{INTRODUCTION}

Language is closely related to mode of thinking, and language is major carrier as well as manifestation pattern of mode of thinking. Therefore, there are also differences between Chinese and English discourses as well. Listening, speaking, reading and writing are four basic English skills of learners in universities and colleges, and English writing is a recreation process of students on the basis of learnt knowledge, so that it is necessary and important in English teaching in universities and colleges. However, present English writing teaching in universities and colleges still pays attention to sentences rather than discourses, so that students have a low ability in organizations and cohesions of English writings. English writing is also a kind of language activity and conceptual work, so that modes of thinking have influence on basic rules of overall planning of English writing. Students' English writing errors in universities and colleges are influenced by Chinese mode of thinking to a great extent, so that this paper firstly discusses the influence of differences in modes of thinking on Chinese and English discourses, and it deeply makes an analysis the implications of differences between Chinese and English discourses on English writing teaching in universities and colleges so as to improve students' ability of English writing in universities and colleges.

\section{DIFFERENCES BETWEEN CHINESE AND AMERICAN MODES OF THINKING}

\section{A. Linear Thinking and Spiral Thinking}

Mode of thinking refers to a kind of inherent language sequence of expressing ideas, and Chinese and English both reflect characteristics of modes of thinking and styles of different countries. Besides, they also reflect social, cultural and psychological trends of China and America as well. English linear thinking belongs to linear thinking, and this kind of mode of thinking firstly originated from history and culture of Plato, Aristotle and ancient Greek. This kind of persuasive speech is direct, and all steps are linked to one another. Its influence on rhetorical forms is reflected in English that English people are idiomatic to use topic sentences in English paragraphs. They are direct in showing their ideas, and then they discuss it in detail, so a conclusion is made at last. Mode of thinking from general to specific is used in English writing in universities and colleges. Chinese people belong to spiral thinking, so that mode of thinking from specific to general is used in English writing by Chinese people. Therefore, they will not start from topics, while English writing is discussed in various other aspects with hints. They are used to state from beginning to end, from details to the whole and from causes to results in their writings.

\section{B. Abstract Thinking and Imaginal Thinking}

American people pay attention to abstract, so that they are good at expressing specific things with abstract concepts, and abstract expressions are commonly seen in English. However, Chinese people prefer to use abstract methods to express abstract concepts, and abstract thinking of pure meanings seems to be meaningless to them. A large number of English words of meaning generalization are used in English to express complex rational concepts such as "drive a bargain". However, specific words are used in Chinese to express the concept of "virtual" such as "feed on illusions". 


\section{DIFFERENCES BETWEEN CHINESE AND ENGLISH DISCOURSE MODES}

The following part makes an analysis differences between Chinese and English discourse modes including differences in topic sentences, cohesion and coherence in discourses as well as endings of discourses.

\section{A. Differences in Topic Sentences}

American mode of thinking pays attention to logical thinking toward things, and they hold a precise view of language so that mode of thinking has a great influence on language. Under the influence of linear thinking, topic sentences are mostly used in English discourses to sum up themes of English writings, and then specific cases as well as details are discussed. American people pay attention to clear determination of topic sentences, so that they are often put in the beginning part of English writings, and this is determined by American cultural thinking mode of self-centered. Themes of English passages can clearly seen in the beginning in a direct way, so that major views are clear and the themes of English writings are also highlighted. Besides, linear development of paragraphs is carried out around the topic, namely central idea is firstly stated, and conclusion is made as last.

Chinese writing mode does not start from topic sentences, but Chinese writings are often stated outside, and it is also developed with repeated spiral structure of certain central idea. Under the influence of Chinese integrative thinking, central ideas and topic sentences are often in the middle or ending parts of Chinese writings, namely that some irrelevant words to central idea of paragraphs are stated in the beginnings, and the topics of English sentences are not discussed quickly. The following is a comparison between Chinese and English writings in terms of topic sentences.

\begin{tabular}{|l|l|l|l|l|}
\hline $\begin{array}{l}\text { Topic } \\
\text { sentence }\end{array}$ & Beginning & Middle & Ending & \\
\hline Chinese & & $11 \%$ & $89 \%$ & \\
\hline English & $99 \%$ & $1 \%$ & & \\
\hline
\end{tabular}

\section{B. Differences in Discourse Cohesion and Coherence}

Both Chinese and English pay attention to cohesion and coherence of discourses, but there are differences between Chinese and English in terms of cohesion and coherence. English thinking mode not only pays attention to the individual person and logical analysis, but also it puts emphasis on language forms. Therefore, American people tend to use explicit cohesion devices such as grammar and conjunctions, and relationships between sentences and paragraphs are reflected in explicit transitional words as well. Therefore, various kinds of conjunctions are widely used in English writings as morphological forms, and transitional words in English writings are often conjunctive adverbs and adverbial phrases.

Chinese people have comprehensive intuition of things on the basis of integrity, and they pay attention to dialectical thinking. Therefore, the relationships between sentences and paragraphs are reflected I logical links aand word orders. If logical relationship can be clearly seen in paragraphs, people tend to use less conjunctions or do not use conjunctions in Chinese writings. Chinese writings pay attention to inner relationship, implicit relationship and implicit relationship rather than strict language structures.

\section{Differences in Endings}

Generally speaking, Chinese writings are personalized, so that writers are a part in writings, and they also hope the readers have the same feelings with them. Thus Chinese writings are relatively subjective, and they often give conclusions and have appeals in the ending parts of writings. However, English writings are relatively objective, and the identities of writers are observers. Therefore, they often use a larger number of data in their writings to show readers the objectivity of writings, so that readers can make conclusions by themselves.

\section{SRATEGIES OF ENGLISH WRITING TEACHING IN UNIVERTIES AND COLLEGE THROUGH DIFFERENCES BETWEEN CHINESE AND AMERICAN DISCOURSES}

Differences between Chinese and English discourses are caused by differences between their modes of thinking, so that teachers in universities and colleges should recognize and makes full use of these differences so as to improve English writing teaching in universities and colleges as well as improve students' comprehensive abilities of using English.

\section{A. Improving Students' Cross-Cultural Consciousness}

Teachers should cultivate students' cross-cultural consciousness in universities and colleges as well as the ability of using English in thinking. In the process of English writing teaching, teachers should not only to grammar and structures of students' writings, but also cultural teaching should be considered as well. Students in universities and colleges can have a better understanding of different characteristics of Chinese and English writings. At the same time, they can improve cross-cultural awareness, cultivate cultural sensibility as well as summarize the features of English culture and mode of thinking in the process of English writing learning in universities and colleges.

\section{B. Analyzing Discourse Structures in Reading Classes}

Although reading is input skill and writing is output skill, there is still close relationship between reading and writing, and writing is established on the basis of reading. Therefore, teachers should make analysis of different discourse structures according to different styles, so that students can have a better understanding of their structures, causes and functions, and they can have enough knowledge in English writing in universities and colleges.

\section{Training Students' English Writing}

In the process of accumulating language materials, teachers should also guide students in universities and colleges do a large amount of English writing exercise at the same time. After that teachers can makes an analysis and give explanations of their English writings so that they can have a better understanding of differences in discourse structures caused by different languages and cultures. Under the influence of Chinese thinking and logic, it is often difficult for Chinese students to use transition words correctly in the process of English writing in universities and colleges, and the use of conjunctions in English 
writings are also ignored. Besides, English writings of Chinese students are also lack of cohesion and coherence, so that they should strengthen training in this these aspects. Moreover, teachers should also correct students' writing tasks and give them feedbacks so that students in universities and colleges can modify on their writings on the basis of this and their English writing abilities can also gradually be improved.

\section{CONCLUSION}

In conclusion, teachers should help students have a better understanding of differences in cultures and modes of thinking in the process of teaching English writing in universities and colleges. Teachers should not only train students' English writing abilities in lexical and grammatical level, but also they should help students know the different characteristics of Chinese and English discourses, so that they cannot be influenced by thinking mode of mother tongue in the process of English writing learning in universities and colleges, and their English writing abilities can also be improved at the same time. Besides, they should encourage students in universities and colleges to appreciate authentic and typical English passages. Moreover, comparative rhetorical knowledge of English discourses can be also applied in reading, listening and second language acquisition so that students' cross-cultual English writing abilities can be improved, and the purpose of using English in communication can be also realized.

\section{REFERENCES}

[1] Connor, U. Contrastive Rhetoric: Cross-cultural aspects of second-language writing. Shanghai: Shanghai Foreign Language Press. 2001.

[2] Halliday \& Hansan, R. Cohesion in English. New York: Longman. 1876.

[3] Kaplan, R. B. Thought Pattern in Intercultural Education. Language Learning. (16):1-20. 1966.

[4] Krashen, S. D. Second Language Acquisition and Second Language Learning. Oxford: Pergamon Press. 1981. a

[5] Krashen, S. D. Writing: Theory and Applications. Oxford: Pergamon Press. 1984.

[6] Martin, J. R. English Text System and Structure. Beijing: Peking University Press 2004.

[7] Mc Carthy, $M$ and Carter, R. Language as Discourse: Perspectives for Language Teaching. Beijing: Peking University Press. 2004.

[8] Mohan, B. A., and W. Lo. Academic Writing and Chinese Students: Transfer and Developmental Factors. TESOL Quarterly 19. (3):515-534. 1985.

[9] Pery-Woodley, M. P. Contrasting Discourses: Contrastive Analysis and a Discourse Approach to Writing. Language Teaching. 23(3):143-151. 1990.

[10] Scollon, R., Scollon, S. W.\& Kirkpatrick, A. Contrastive Discourse in Chinese and English-A Critical Appraisal. Beijing: Foreign Language Teaching and Research Press. 2000b. 